\title{
Speech profile in Down syndrome: speech apraxia $x$ speech disorder of musculoskeletal origin
}

\author{
Julyane Feitoza Coêlho' \\ https://orcid.org/0000-0003-3632-2653 \\ Isabelle Cahino Delgado' \\ https://orcid.org/0000-0002-0800-559X \\ Marine Raquel Diniz da Rosa' \\ https://orcid.org/0000-0003-0920-2234 \\ Giorvan Ânderson dos Santos Alves ${ }^{1}$ \\ https://orcid.org/0000-0003-1619-0139
}

Universidade Federal da Paraíba, João Pessoa, Paraíba, Brasil.

Conflict of interests: Nonexistent

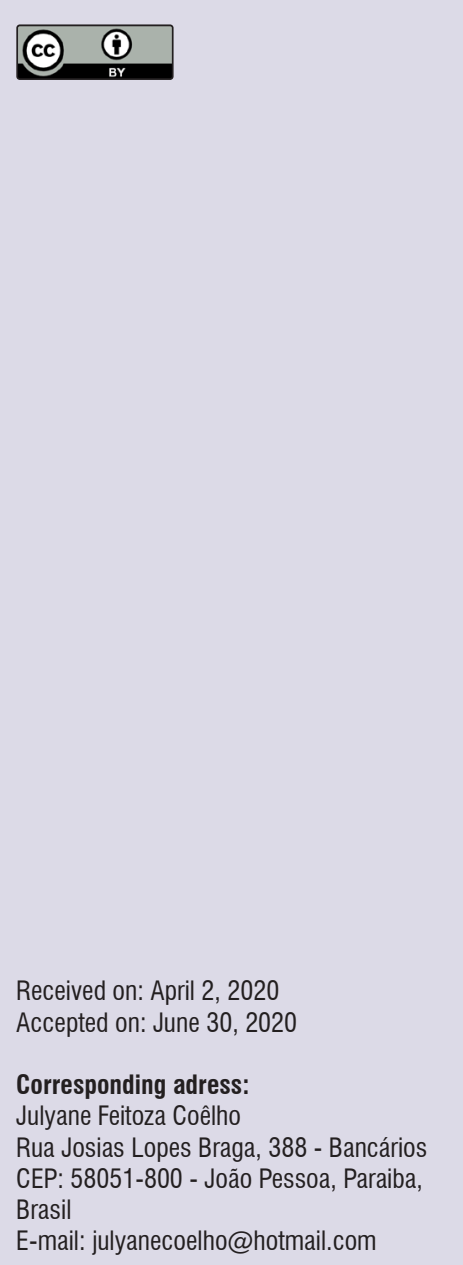

\section{ABSTRACT}

This study presents an analysis of linguistic aspects at the segmental and suprasegmental levels in individuals with Down syndrome with or without a diagnosis of speech apraxia. Ten individuals of both sexes, aged between 13 and 32 years, participated in the study. Data collection was performed, individually and separately, in a video recorded therapeutic session. Speech tasks consisted of word repetition, repetition of sentences and automatic speech. The speech samples were submitted to phonetic transcription with a description and analysis of phonoarticulatory alterations, typology of disfluencies and prosodic alterations. The data were submitted to descriptive and inferential statistical analysis, using the Mann-Whitney test for independent samples and considering $p$-value $\leq 0.05$ as significant. Individuals with speech apraxia $(n=6)$, compared with those without it $(n=4)$, presented a higher occurrence of phonoarticulatory alterations, with a statistically significant difference between the two groups in omission $(p=0.018)$ and articulatory inaccuracy $(p=0.030)$ alterations; a higher occurrence of disfluencies, mainly of the syllable repetition type; and the occurrence of prosodic alterations (83.3\%), which was not found in the group without speech apraxia. The importance of the differential diagnosis of speech disorders in Down syndrome is revealed with an evaluation that considers the different linguistic aspects resulting from the differentiation of the characteristics of speech. Clinical intervention should be early and guided by specific parameters.

Keywords: Down Syndrome; Apraxia; Speech, Language and Hearing Sciences; Linguistics; Speech 


\section{INTRODUCTION}

Down syndrome (DS) is a genetic condition characterized by a change in the distribution of chromosomes in the cells, presenting an extra copy of chromosome 21 that causes an imbalance of the regulatory function that genes exert on protein synthesis, resulting in a loss of harmony in the development and functions of cells. These deficits are present from intrauterine development and will characterize the individual throughout his life, consequently resulting in several characteristics, primarily intellectual deficit and morphofunctional alterations".

Cognitive and language development occurs slower and more delayed in children with DS than in children without the pathology, with greater impairments associated with linguistic aspects. Despite knowledge of the delay in language development predicted in DS - particularly at the lexical, pragmatic and phonological levels - the nature of such difficulties in the acquisition process is not well established ${ }^{2}$. Phonoarticulatory abilities may be a necessary precursor for language skills; that is, language disorders and dysfunction of the oral motor sensory system often occur simultaneously $^{3}$. In language development in individuals with DS, comprehension develops better than expression, with particular challenges in phonology and syntax, indicating the existence of greater impairments associated with the realization of the motor act of speech.

Speech difficulties in DS are very noticeable, so, these difficulties must be analyzed in a perceptual, motor and linguistic context and may be related to peripheral and central-level factors. Furthermore, it is likely that several factors interact in the development and persistence of these alterations, such as sensory deficits, neurological dysfunctions and the oral motor sensory system ${ }^{4}$.

Individuals with DS present with a reduction in the size of the oral cavity, alterations in the organs that make up the stomatognathic system, phonoarticulatory disorders due to difficulties or impediments in the articulation and alterations in phonation ${ }^{3}$. Stomatognathic alterations have implications for speech, modifying virtually all the articulatory points of consonants and characterizing a speech disorder of musculoskeletal origin, in which speech alterations originate due to structural bone and muscle changes. In addition, this speech disorder is associated with the presence of oral breathing in these individuals, a respiratory mode that favors bone, muscle and postural changes.
Moreover, the speech characteristics of people with DS may be altered not only by the characteristics of the stomatognathic system of these individuals but also by difficulties in the programming of movements and sequencing necessary for the production of speech sounds. A person with DS may demonstrate a compromise in the ability to voluntarily program speech movements, that is, when communicating, the individual knows which words he wishes to emit; however, he is not able to perform postural programming of the phonoarticulatory structures and the planning of the sequence of articulatory movements appropriate to the production of the related sounds. Associated with this aspect, there is a decrease in speech intelligibility, inconsistency in errors, and difficulties in the sequentialization of oral sounds and movements, aspects that clinically characterize speech apraxia.

The prevalence of different types of speech disorders and motor speech disorders was investigated in individuals with DS through the analysis of speech samples from 45 participants aged between 10 and 20 years using perceptual and acoustic methods and measures from the Speech Disorders Classification System. In total, $97.8 \%$ of the participants met the criteria for motor speech disorders, including childhood dysarthria (37.8\%), speech motor delay (26.7\%), a combination of childhood dysarthria and childhood apraxia of speech (22.2\%), and childhood apraxia of speech alone (11.1\%). It can be verified that almost all participants presented with motor speech disorders, demonstrating the importance of conducting studies in this area, as well as the relevance of considering these aspects in the evaluation, with implications for the therapeutic process ${ }^{5}$.

In view of the above, we performed a speech analysis of people with DS with or without a diagnosis of speech apraxia, describing and characterizing the existing alterations at the segmental and suprasegmental levels. As specific objectives, we sought to investigate the phonological level of language, observing the possible deviations and the phonetic aspects contributing to the occurrence of articulatory alterations; to identify the occurrence and typology of the disfluencies present in the participants' speech; to check for prosodic changes; and to correlate the findings with the cognitive, perceptual, linguistic and motor aspects characteristic of Down syndrome. 


\section{CASES REPORT}

Ethical aspects were considered with respect to resolution 466/12 of the National Health Council. The research project was submitted to the Ethics Committee on Research with Human Beings of the Centro de Ciências da Saúde da Universidade Federal da Paraíba and subsequently evaluated and approved, with opinion number $1,302,829$. During the collection, a copy of the Free and Informed Consent Form was presented to the legal representative of the volunteer (for children under 18 years of age) and to the volunteer (for those over 18 years old), preserving the confidentiality of all data collected. In the case of a minor, a form for obtaining the assent of the minor as also presented.
The study was carried out in the Clinic-School of Speech Therapy of the institution of origin, located in the city of João Pessoa, PB, Brazil. The study sample consisted of 10 individuals with Down syndrome who were participants of the university extension program "Literacy in Agenda: Speech Therapy Intervention in Subjects with Down Syndrome", aged between 13 and 32 years, divided into two groups: people diagnosed with speech apraxia (6 individuals) and people without a diagnosis of apraxia but with speech disorder of musculoskeletal origin (4 individuals). Five individuals were females, with a mean age of 19.6 years, and five were males, with a mean age of 17.8 years. The characterization of the participants of each group regarding gender and age is available in Figure 1.

\begin{tabular}{|c|c|c|c|}
\hline Identifier & Diagnosis & Sex & Age \\
\hline A1 & Speech Apraxia & $\mathrm{F}$ & 19 \\
\hline $\mathrm{A} 2$ & Speech Apraxia & $\mathrm{F}$ & 15 \\
\hline $\mathrm{A} 3$ & Speech Apraxia & $\mathrm{F}$ & 16 \\
\hline $\mathrm{A} 4$ & Speech Apraxia & $\mathrm{M}$ & 17 \\
\hline $\mathrm{A} 5$ & Speech Apraxia & $\mathrm{M}$ & 17 \\
\hline $\mathrm{A} 6$ & Speech Apraxia & $\mathrm{F}$ & 25 \\
\hline $\mathrm{T} 1$ & Speech Disorder of Musculoskeletal Origin & $\mathrm{F}$ & 32 \\
\hline $\mathrm{T} 2$ & Speech Disorder of Musculoskeletal Origin & $\mathrm{M}$ & 16 \\
\hline T3 & Speech Disorder of Musculoskeletal Origin & $\mathrm{M}$ & 17 \\
\hline T4 & Speech Disorder of Musculoskeletal Origin & 13 \\
\hline
\end{tabular}

Legend: Female (F); Male (M); Apraxia (A); Speech Disorder of Musculoskeletal Origin (T).

Figure 1. Characterization of participating individuals by group

The inclusion criteria were the presence of oral verbal language and cognitive development necessary to perform the tests of the data collection instrument. These cognitive aspects were evaluated based on specific extension project protocols. To compose the two study groups, individuals with DS and a diagnosis of speech apraxia in childhood or speech disorder of musculoskeletal origin were selected.

The diagnosis of speech alteration for the participants was obtained through global evaluation using the MBGR Protocol ${ }^{6}$, which consists of the individual's clinical history, an orofacial myofunctional examination, involving the evaluation of organs and functions of the stomatognathic system through visual inspection, palpation, measurements and functional analysis, and the Protocol for The Evaluation of Speech Apraxia ${ }^{7}$, consisting of tests for the evaluation of nonverbal praxia with requests for isolated and sequential movements, performed after verbal command. In the test for the evaluation of verbal praxia, the protocol consists of tasks of repetition of words and sentences, automatic speech, spontaneous speech and the reading aloud of words and sentences.

The speech sample data were submitted to manual phonetic transcription; speech-language changes, disfluency typology and prosodic classification were identified, selected and described through the subjective evaluation of the principal researcher, specialist speech therapist and clinical expert in the field.

The speech characteristics of the individuals were divided into the following dimensions: Speech (transcription of the speech sample of the participants), Articulation (phonoarticulatory alterations, classified as addition, substitution, distortion, omission and articulatory inaccuracy) $)^{8}$, Fluency (typology of disfluencies) ${ }^{9}$ 
and Prosody (classified as normal or altered, from the observation of atypical patterns of accentuation, intonation and rhythm $)^{10}$.

The results obtained from the evaluations of the participants were analyzed quantitatively. The phonoarticulatory alterations, the typology of disfluencies and the prosodic classification obtained from the data of the speech apraxia evaluation tests were identified and submitted to descriptive statistics. Subsequently, the data were submitted to inferential statistics to compare the results obtained from the two groups of the study sample.

The descriptive and inferential analysis was performed using statistical software R, version 3.2.5. A significance level of $95 \%$ reliability was adopted. Initially, descriptive statistical analysis was performed to verify the means and standard deviations of the variables studied. Then, hypothesis tests were performed using the Mann-Whitney nonparametric test for independent samples to compare the two groups analyzed in this study.

\section{RESULTS}

Analysis of the phonoarticulatory alterations and typology of the disfluencies observed in each group and the intergroup comparisons are presented in Table 1.

Table 1. Intergroup comparisons of identified phonoarticulatory alterations and disfluencies

\begin{tabular}{lccccc}
\hline \multirow{2}{*}{ Variable } & \multicolumn{2}{c}{ Apraxia Group } & \multicolumn{2}{c}{ Musculoskeletal Disorder Group } & \multirow{2}{*}{ P-value } \\
\cline { 2 - 4 } & Mean & SD & Mean & SD & \\
\hline Omission & 12.33 & 4.13 & 2.25 & 2.62 & $0.018^{*}$ \\
Replacement & 12.7 & 6.94 & 5.75 & 4.92 & 0.164 \\
Addition & 0.16 & 0.40 & 0.25 & 0.50 & 0.878 \\
Distortion & 0 & 0 & 0.50 & 1 & 0.307 \\
Articulatory inaccuracy & 4.5 & 4.28 & 0 & 0 & $0.030^{\star}$ \\
Repetition of sounds & 0.16 & 0.40 & 0 & 0 & 0.543 \\
Repetition of words & 0.50 & 1.22 & 0 & 0 & 0.543 \\
Repetition of syllables & 1 & 1.54 & 0.50 & 1 & 0.692 \\
Block & 0.16 & 0.40 & 0 & 0 & 0.540 \\
Extension & 0.16 & 0.40 & 0.25 & 0.50 & 0.878 \\
Intrusion & 0.16 & 0.40 & 0.25 & 0.50 & 0.878 \\
\hline
\end{tabular}

Legend: SD: Standard deviation; Mann-Whitney U test. ${ }^{*} \mathrm{p}$-value $\leq 0.05$.

The frequency of the phonoarticulatory alterations produced by each participant is shown in Figure 2. In individuals diagnosed with speech apraxia, there was a predominance of omission $(p=0,018)$ and substitution $(p=0,030)$ alterations, and statistically significant differences were found between the two groups in the occurrence of omission and articulatory inaccurate alterations. In the group of participants without speech apraxia, diagnosed with speech disorder of musculoskeletal origin, the individuals also presented examples of substitution and omission, but with a much smaller occurrence, in addition to examples of distortion and addition.

The distribution and typology of disfluencies were observed in a lower occurrence. In the apraxia group, participant A1 presented only one repetition of sounds;
A2 produced word repetition (3), syllable repetition (3) and block (1); A3 produced only one extension; A4 presented with repetition of syllables (3) and intrusion (1); participants A5 and A6 did not present with any disfluency. In the group with speech disorder of musculoskeletal origin, participant T2 presented with repetition of syllables (2) and prolongation (1); participant T3 presented with intrusion (2); and participants $\mathrm{T} 1$ and $\mathrm{T} 4$ did not produce disfluencies. The group of individuals with apraxia, when compared with the group with speech disorder of musculoskeletal origin, had a higher occurrence of disfluencies, mainly of the repetition type of syllables and words; however, the results were not statistically significant. In both groups, the presence of common disfluencies of the hesitation, interjection, 


\begin{tabular}{|c|c|c|c|c|c|}
\hline Identifier & Omission & Replacement & Addition & Distortion & $\begin{array}{c}\text { Articulatory } \\
\text { Inaccuracy }\end{array}$ \\
\hline $\mathrm{A} 1$ & 16 & 10 & 0 & 0 & 6 \\
\hline $\mathrm{A} 2$ & 14 & 15 & 0 & 0 & 12 \\
\hline $\mathrm{A} 3$ & 11 & 19 & 1 & 0 & 7 \\
\hline $\mathrm{A} 4$ & 06 & 19 & 0 & 0 & 3 \\
\hline $\mathrm{A} 5$ & 10 & 1 & 0 & 0 & 0 \\
\hline $\mathrm{A} 6$ & 17 & 9 & 0 & 0 & 2 \\
\hline $\mathrm{T} 1$ & 1 & 0 & 0 & 0 & 0 \\
\hline $\mathrm{T} 2$ & 0 & 5 & 0 & 2 & 0 \\
\hline $\mathrm{T} 3$ & 2 & 6 & 1 & 0 & 0 \\
\hline $\mathrm{T} 4$ & 6 & 12 & 0 & 0 & 0 \\
\hline
\end{tabular}

Legend: Apraxia (A); Speech Disorder of Musculoskeletal Origin (T).

Figure 2. Frequency of phonoarticulatory changes

revision and unfinished word type or of stuttering disfluencies of the pause type was not observed.

Prosody was classified as normal or altered for individuals in both groups. A total of $83.3 \%$ of the individuals with apraxia presented with altered prosody, and only one - participant A6 - presented with normal prosody. In the group with speech disorders of musculoskeletal origin, none of the participants showedprosodic alterations.

\section{DISCUSSION}

As a general characteristic of speech apraxia, the most common articulatory failures are related to substitutions, followed by omissions, inversions, additions, repetitions, distortions and prolongations of phonemes. The involvement occurs primarily in the articulation and secondarily in prosody. The omission of sounds more specifically distinguishes childhood apraxia of speech $^{11}$, corroborating the results of our study, in which individuals with Down syndrome and a diagnosis of apraxia presented with a significantly higher occurrence of omissions than the group diagnosed with speech disorder of musculoskeletal origin.

Our results are also similar to those of a study conducted to compare and analyze the repair strategies used by twenty-one children with typical or atypical phonological acquisition and with speech apraxia, which found that the group with apraxia tended to omit syllables, perform both the usual substitutions and, mainly, idiosyncratic substitutions and assimilation ${ }^{12}$.

According to the literature, problems related to the anatomy of the phonatory apparatus, one of the characteristics of DS, compromise the harmonious movement of articulators, and orofacial hypotonia is one aspect, among others, that hinders the motor programming of sounds, triggering phonetic changes. In addition, cognitive deficit, another factor inherent to the syndrome, is responsible for aggravating articulatory alteration: neurological immaturity limits the memorization and motor programming of sound chains ${ }^{13}$.

In the group of individuals with DS and speech disorder of musculoskeletal origin, phonoarticulatory alterations were also found, but in a smaller number, and may be associated with the characteristics of the stomatognathic system and existing sensory deficits, aspects that generate difficulties or impediments in the articulation and alteration of phonation, compromising speech. The phonoarticulatory disorders found in people with DS are commonly associated with muscle hypotonia, which, when accentuated, can cause decreased movement of the phonoarticulatory organs (OFAs), reflected in articulatory inaccuracies, substitutions or distortions of sounds.

Muscle hypotonia also causes an imbalance of the forces between the oral and facial muscles, altering the dental arch, resulting in an aspect of mandibular projection and contributing to the tongue assuming an inadequate position. Oral breathing, in addition to making the child more susceptible to respiratory infections, alters the shape of the palate and makes it difficult for him to articulate sounds. The main characteristics that predispose these children to difficulties with speech are hypotonia and oral breathing ${ }^{3}$.

In addition to the hypotonia of the orofacial musculature, peculiar craniofacial complex characteristics are also found: a small and narrow palate, pseudomacroglossia, cleft tongue, underdevelopment of the 
maxilla and middle third of the face, a small nose, a flat or prognathous facial profile and ligament hyperflexibility ${ }^{14}$. In individuals with pseudomacroglossia, all phonemes using the tongue are impaired. Hypernasality, a common feature in Down syndrome, which may be caused by the alteration in velopharyngeal sphincter mobility, may lead to changes in voice quality and speech intelligibility. The impairment and changes resulting from inadequate craniofacial growth lead to disorders in the production of speech as a whole. Dentofacial deformities can include open bite, cross- and overbite, as well as angle class I, II and III facial growth patterns, altering mandibular movements and influencing speech patterns. Another common characteristic in these individuals is dental crowding and the absence of teeth, facilitating inadequate tongue movements and influencing the passage of air through the oral cavity and diastema, as well as accumulation of saliva in the cavity causing whistles and changes in speech intelligibility.

In a study conducted with 5 adults with Down syndrome that sought to identify speech intelligibility deficits and search for error profiles based on listeners, a word intelligibility test was used, verifying that the main changes were the simplification of consonants in the initial and final positions of words and contrasts involving tongue positioning, control and duration ${ }^{15}$. These results correspond with our study regarding the identification of the occurrence of substitution type alterations as recurrent in the speech of individuals with Down syndrome, generating impairments in communication and speech intelligibility.

Phonological accuracy and speech intelligibility were investigated in boys with Down syndrome, fragile $X$ syndrome associated with autism spectrum disorder, fragile $X$ syndrome only, and typical development, verifying that boys with Down syndrome obtained lower results in measures of phonological accuracy and occurrence of phonological processes than the other groups and used fewer intelligible words than boys with typical development ${ }^{16}$, which may be associated with oromyofunctional alterations characteristic of Down syndrome as well as difficulties in planning and programming the movements necessary for the proper realization of the motor act of speech.

In a study conducted with 45 adolescents with Down syndrome to identify the associations between motor speech disorders and intelligibility, low intelligibility was significantly associated with general reductions in phonemic and phonetic accuracy and with prosody and voice inadequacies. Among the participants, five presented with a diagnosis of childhood apraxia of speech, three of whom presented with reduced intelligibility, none with moderate intelligibility and two with high intelligibility. The results showed that reduced intelligibility was not significantly associated with the demographic, intelligence or language variables evaluated in the study. Significantly more participants with dysarthria or apraxia presented with reduced intelligibility, as observed in the analysis of groups of participants with dysarthria, apraxia, or combined dysarthria and apraxia ${ }^{17}$. In this sense, phonoarticulatory alterations, found mainly in individuals with speech apraxia in our study, can have a significant impact on speech intelligibility, which then impacts oral communication.

The perceptual characteristics of speech were described in a study on twenty-six children with DS, identifying that the most compromised characteristics were naturalness, inaccurate consonants, hyponasality, speech rate, inappropriate silences, irregular vowels, prolonged intervals, general intensity level, frequency level, oropharyngeal resonance, hoarse voice, reduced stress and prolonged phonemes. The findings suggest that speech disorders in DS are due to distributed impairments involving voice, speech sound production, fluency, resonance and prosody ${ }^{18}$.

Fluency can be considered a speech performance descriptor, differentiating itself from other components of language by characterizing an automatic pattern that makes it possible for a speech to be perceived as uninterrupted. Speed can be understood as a measure of the amount of speech produced in a given time. Speech smoothness is the result of effortless motor production and transition. Fluency and smoothness of speech result from practical learning; consequently, as motor programs are performed, corrected and repeated, the acts become natural ${ }^{19}$.

The intellectual impairment present in individuals with DS contributes to a higher mean prevalence of stuttering than the general population. Despite being considered a primary symptom in several genetic syndromes, the data on fluency are still unclear, which prevents the differentiation of stuttering from the development of stuttering associated with this alteration $^{20}$. Stuttering is perpetuated through adulthood in individuals with Down syndrome; one may think that due to motor impairment and difficulty in the development at the phonological level, the individual incorporates the pattern of disfluency into his speech rhythm ${ }^{21}$. 
In this sense, with regard to fluency and prosody, in an elaborate review study, it was concluded that stuttering, a communication disorder characterized by involuntary speech interruption that affects, on average, $1 \%$ of the general population but 10 to $40 \%$ of the Down syndrome population. These studies point to significant prosodic disturbances ${ }^{4}$. In another study, 76 individuals with Down syndrome, aged between 3.8 and 57.3 years, were evaluated by the Predictive Cluttering Inventory; $78.9 \%$ obtained a score that classified them as dysfluent, and $17.1 \%$ were qualified as stutterers ${ }^{22}$.

Speech disfluencies were also analyzed in the spontaneous speech of twenty-six children with DS aged between 3 and 13 years. Approximately 30\% of children with DS presented with stuttering; in addition, there was a difference in the distribution of the types of disfluencies. The younger age group of children with DS presented proportionally more common disfluencies, while the older age group presented proportionally more stuttering disfluencies, pointing to a developmental trend. In the analysis of the typology considered for the classification of disfluencies, it was observed that most participants presented with interjections, repetitions of multisyllabic words and prolongations. Repetitions of single-syllable words, blocks, repetitions of sentences and partial repetitions of words were observed in approximately half of the participants. Revisions occurred in the speech of only approximately a quarter of the participants, and word breaks were heard only in a few speech samples ${ }^{23}$. In our study, different patterns were observed, with a higher occurrence of disfluencies in the group with DS and associated apraxia, mainly of the repetition of syllables and words. Prolongations were observed in two participants, while neither group displayed interjection and revision disfluencies.

In individuals with apraxia, the lack of fluency in speech is primarily caused by pauses and hesitations, which occur in an attempt to correctly produce words, emerging as a form of compensation for the continuous difficulty in articulation ${ }^{24}$. Unlike the above, in the present study, there was no indication of hesitation or pause disfluencies in individuals evaluated with DS and apraxia, inconsistent with the results of the previous study, which may indicate different patterns of fluency in speech apraxia associated with Down syndrome, with a tendency of participants to predominantly make omissions and articulatory inaccuracies as adjustments in the face of difficulties in phoneme production, with lower impairments to speech fluency. The results found in our study may also represent particular characteristics of the research participants, which hinders generalizations due to the small sample size.

For the diagnosis of speech apraxia, it is important to consider the segmental characteristic of articulatory groping, especially at the beginning of speech; substitution errors, characterized mainly by metasis; inconsistent speech exchanges; and a greater number of vowel errors. Suprasegmental characteristics are also worth mentioning, including inconsistent realization of stressed syllables and nasopharyngeal resonance perception ${ }^{25}$. When considering the specific context of DS, other considerations are also important for the differential diagnosis of the type of speech disorder due to the specific characteristics associated with the phenotype of the syndrome and the possibility of cooccurrence with other disorders.

Sensory deficits, such as hearing loss itself, are organic factors that influence the communication of individuals with Down syndrome. In a study conducted with 15 individuals, most children presented with middle ear alterations and conductive hearing loss. This deficiency significantly impairs the monitoring of individuals with the syndrome at the phonoarticulatory and prosodic levels due to the absence of auditory feedback ${ }^{26}$. These difficulties of perceptual origin linked to changes in the phonoarticulatory organs contribute to changes in speech fluency and prosody.

Prosodic aspects comprise several acoustic elements that form intonation and are also associated with the rhythm of speech, being important for the transmission of emotions and the senses involved in communication. Prosodic abilities were investigated in a study with nine children with Down syndrome (ranging from 45 to 63 months and with a mean age of development of 30 months) and twelve children with typical development and equivalent age by recording spontaneous productions during observations of mother-child play sessions. Data analysis showed that despite their morphosyntactic difficulties, the children with DS were able to master some aspects of prosody in utterances with several words, producing unique intonations in utterances with several words at the same level as the children with typical development. Moreover, the intonational contour of their expressions was not negatively influenced by syntactic complexity, contrary to what occurred in children with typical development, although it is necessary to consider that the utterances produced by the children with DS were less complex than those produced by the children in the 
control group. However, the children with DS seemed to be less able to use intonation to express pragmatic interrogative functions ${ }^{27}$.

A perceptual and acoustic evaluation of prosody was performed in three individuals with DS aged between 16 and 44 years. Several perceptual parameters were classified as diverging from the normal range, in particular the frequency level (abnormally low), monopitch, monoloudness, speech rate and stress expression. The acoustic analysis showed a higher mean F0 in spontaneous speech for participants with DS, and the larger F0 intervals observed in the speech of participants with DS may reflect inconsistency in motor control during speech. Regarding mean amplitude and amplitude variability, all participants were within the mean range for the mean amplitude of the conversation level. In addition, the three participants with DS had a greater amplitude interval than their respective controls, indicating greater volume variation in speech, which may also be associated with difficulties in motor control ${ }^{28}$.

Different aspects of intonation and phonation in the speech of people with Down syndrome were acoustically analyzed. The results of intonation and phonation spectrography indicated that young people and adults with Down syndrome present with a reduction in organic and laryngeal tessitura, little melodic variation and reduced intonation patterns ${ }^{29}$. In our study, we observed the occurrence of prosodic alterations only in the group of individuals with Down syndrome associated with speech apraxia, a result consistent with the criteria of diagnostic validity of apraxia, which consider inadequate prosody as one of the three widely recognized characteristics, along with inconsistent unusual substitutions and difficulties in initial articulatory configurations or transition movements.

Considering speech apraxia as a neurological disorder of speech sounds, which is characterized by changes in the parameters of planning and/or spatialtemporal programming of movement sequences, which results in errors in speech production and prosody, the aspects found in individuals with Down syndrome and apraxia corroborate those already described in the literature in the field. The results of the present study highlight the importance of observing difficulties in programming and sequencing speech movements in individuals with Down syndrome because the speech characteristics of these people may be altered due to multiple factors, such as the specific characteristics of the stomatognathic system and neurological reasons, which include delay in cognitive development.

The speech apraxia found in these individuals may be related to several neurological impairments, which also justify the numerous cognitive challenges observed. Individuals with DS, compared with those with typical development, present with marked differences in general cognitive functioning. Evidence from neuroimaging studies suggests that cognitive deficits experienced by children with DS are associated with structural and functional neuroanatomical abnormalities. Some of these abnormalities include fewer dendritic branches in the brain, fewer synapses and reduced functional brain connectivity found in many newborns with DS; studies with older children and young adults with DS indicate reduced brain volume, with specific reductions in the cerebellum and frontal and temporal regions; and studies with school-age children and models of mice with DS reveal a significant dysfunction in the hippocampus, which has also been associated with general cognitive ability ${ }^{30}$.

Our results indicate that the linguistic aspects at the segmental and suprasegmental levels are different in individuals with DS, according to the alterations present in speech disorder of musculoskeletal origin or speech apraxia, which is fundamental for the differential diagnosis for the establishment of adequate therapeutic conduct and clinical progress. Diagnosis can be difficult, especially when this disorder is comorbid with other speech and language abnormalities associated with the syndrome. Therefore, the study and evaluation of the various linguistic levels can collaborate in this process, contributing to a better understanding of the process of language acquisition and development in these individuals.

\section{FINAL CONSIDERATIONS}

The present study indicated that individuals with Down syndrome and a diagnosis of apraxia, compared with individuals without speech apraxia but with speech disorder of skeletal muscle origin, present with a considerably higher occurrence of phonoarticulatory alterations; a higher occurrence of disfluencies, especially syllable repetition; and finally, the occurrence of prosodic alterations (83.3\%), which were absent in the group with speech disorder of musculoskeletal origin.

This research brings relevant contributions regarding linguistic characteristics in the different speech alterations (of musculoskeletal and neurological origin) in people with DS. In addition, it provides 
perspectives for further studies on the theme, taking into account the small number of national publications addressing speech apraxia, a clinical condition that has severe repercussions for the speech of individuals and presents itself as one of the most difficult and prolonged speech pathologies with regard to treatment.

It is recommended that studies be conducted with larger samples that characterize the various linguistic levels (pragmatic, morphosyntactic, phonological and semantic), according to the different speech alterations. It is extremely important that a differential diagnosis of the alterations in the speech of individuals with Down syndrome be performed, and thus, in this perspective, studies that can identify clinical markers associated with the speech production of these individuals would be relevant.

\section{REFERENCES}

1. Silva MFMC, Kleinhans ACS. Processos cognitivos e plasticidade cerebral na síndrome de Down. Marília. Rev. Bras. Ed. Esp. [Internet]. 2006 [cited 2018 July 13]; 12(1):123-38. Available from: http:// www.scielo.br/pdf/rbee/v12n1/31988.pdf.

2. Naess KB, Lyster SH, Hulme C, Melby-Lervåg $M$. Longitudinal relationships between language and verbal short-term memory skills in children with Down syndrome. J Exp Child Psychol. 2015;24(135):43-55.

3. Barata LF, Branco A. Os distúrbios fonoarticulatórios na síndrome de Down e a intervenção precoce. Rev. CEFAC. [Internet]. 2010 [Acesso em: 10 jan. 2018]; 12(1):134-9. Disponível em: http://www. scielo.br/pdf/rcefac/v12n1/a18v12n1.pdf.

4. Kent RD, Vorperian HK. Speech impairment in Down syndrome: a review. Speech Lang Hear Res. [Internet]. 2013 [ cited 2018 Jan 10]; 56(1):178-210. Available from: https://jslhr.pubs.asha.org/article. aspx?articleid $=1782045$.

5. Wilson EM, Abbeduto L, Camarata SM, Shriberg LD. Estimates of the prevalence of speech and motor speech disorders in adolescents with Down syndrome, Clinical Linguistics \& Phonetics. 2019;33(8):772-89. DOI: 10.1080/02699206.2019.1595735.
6. Genaro KF, Berretin-Felix G, Rehder MIBC, Marchesan IQ. Avaliação miofuncional orofacial: protocolo MBGR. Rev. CEFAC [Internet]. 2009 June [cited 2018 Jun 03];11(2):237-55. Available from: http://www.scielo.br/scielo.php?script $=$ sci arttext\&pid=S1516-18462009000200009\&Ing $=$ en. http://dx.doi.org/10.1590/S1516-18462009000200009.

7. Martins FC, Ortiz KZ. Proposta de protocolo para avaliação da apraxia de fala. Fono Atual. 2004;7(30):53-61.

8. Zorzi JL. Diferenciando alterações da fala e da linguagem. In: Marchesan IQ (org). Fundamentos da Fonoaudiologia: aspectos clínicos da motricidade oral. 2 ed. Rio de Janeiro: Guanabara Koogan; 2005.p. 69-85.

9. Andrade CRF. Fluência. In: Andrade CRF, Befi-Lopes DM, Fernandes FDM, Wertzner HF (orgs). ABFW: teste de linguagem infantil nas áreas de fonologia, vocabulário, fluência e pragmática. Carapicuiba: Pró-Fono, 2000. c. 3, p. 61-70.

10. Fish M. Avaliação de crianças com suspeita de apraxia de fala na infância. In: Fish M (org). Como tratar a apraxia de fala da infância. Carapicuíba: Pró-Fono; 2019. p. 25-58.

11. Souza TNU, Payão LMC. Apraxia da fala adquirida e desenvolvimental: semelhanças e diferenças. Rev. soc. bras. fonoaudiol. [Internet]. 2008 June [cited 2018 July 01]; 13(2):193-202. Available from: http:// www.scielo.br/scielo.php?script $=$ sci_arttext\&pid= S1516-80342008000200015\&lng=en. http://dx.doi. org/10.1590/S1516-80342008000200015.

12. Mezzomo CB, Vargas DZ, Souza APR. As diferenças na produção correta e no uso das estratégias de reparo em crianças com desenvolvimento fonológico típico, atípico e com dispraxia. Distúrb. Comun. [Internet]. 2011 [citado 2018 Jul 12]; 23(3):261-7. Disponível em: https://revistas.pucsp. br/index.php/dic/article/view/9103.

13. Silva CAPPG. Transtornos fonético-fonológicos na Síndrome de Down e implicações na lectoescrita. SCRIPTA. 2010;14(26):57-70.

14. Areias $C$, Pereira ML, Pérez-Mongiovi D, Macho V, Coelho A, Andrade D et al. Enfoque clínico de niños con síndrome de Down en el consultorio dental. Av Odontoestomatol. [Internet]. 2014 Dic [citado 2018 Jul 18]; 30(6):307-13. Disponible en: http://scielo.isciii.es/scielo.php?script $=$ sci arttext\&pid $=$ S021312852014000600003\&lng=es.

15. Bunton K, Ledd M, Miller J. Phonetic intelligibility testing in adults with Down syndrome. Downs 
Syndr Res Pract. [Internet]. 2007 [acesso em: 06 jan. 2018];12(1):1-4. Disponível em: https://www. ncbi.nlm.nih.gov/pmc/articles/PMC2805101/.

16. Barnes E, Roberts J, Long SH, Martin GE, Berni MC, Mandulak KC et al. Phonological accuracy and intelligibility in connected speech of boys with fragile $X$ syndrome or Down syndrome. Speech Lang Hear Res. 2009;52(4):1048-61. Disponível em: https:// jslhr. pubs.asha.org/article. aspx?articleid $=1779875$.

17. Wilson EM, Abbeduto L, Camarata SM, Shriberg LD. Speech and motor speech disorders and intelligibility in adolescents with Down syndrome. Clinical Linguistics \& Phonetics. 2019;33(8):790814. DOI: 10.1080/02699206.2019.1595736.

18. Jones HA, Crisp KD, Kuchibhatla M, Mahler L, Risoli $\mathrm{Jr} \mathrm{T}$, Jones CW et al. Auditory-perceptual speech features in children with Down syndrome. AAIDD Online Journal. 2019;124(4):324-38.

19. Juste FS, Ritto AP, Silva KGN, Andrade CRF. Sequential diadochokinesis in fluent and stuttering children: rate of production and type of errors. Audiol., Commun. Res. [Internet]. 2016 [cited 2020 June 29]; 21:e1646. Available from: http://www.scielo. $\mathrm{br} / \mathrm{scielo}$. php? script $=$ sci_arttext\&pid $=$ S2317 64312016000100310\&Ing=en. Epub May 31, 2016. https://doi.org/10.1590/2317-6431-2015-1646.

20. Borsel JV, Tetnowski JA. Fluency disorders in genetic syndromes. J Fluency Disord. [Internet]. 2007 [acesso em: 09 jan. 2018]; 32(4):279-96. Disponível em: https://www.sciencedirect.com/ science/article/pii/S0094730X07000411.

21. Rangel DI, Ribas LP. Características da linguagem na síndrome de Down: implicações para a comunicação. Rev. Conhecimento Online. [Internet]. 2011 [cited 2018 July 17];2:18-29. Available from: http://periodicos.feevale.br/seer/ index.php/revistaconhecimentoonline/article/ view/170.

22. Borsel JV, Vandermeulen A. Cluttering in down Syndrome. Folia Phoniatrica et Logopaedica. [Internet]. 2008 [acesso em: 09 jan. 2018]; 60(6):312-7. Disponível em: https://www. researchgate.net/publication/23475636_Cluttering_ in_Down_Syndrome.

23. Eggers K, Van Eerdenbrugh S. Speech disfluencies in children with Down syndrome. J Desordem Comunitária. 2018;71(1):72-84.

24. Metter EJ. Relação cortical dos distúrbios da fala. In: (org). Distúrbios da fala: avaliação clínica e diagnóstico. Rio de Janeiro: Enelivros; 1991. p.179-83.

25. Shriberg LD, Fourakis M, Hall SD, Karlsson HB, Lohmeier HL, McSweeny JL et al. Extensions to the Speech Disorders Classification System (SDCS). Clin Linguist Phon. [Internet]. 2010 [cited 2018 July 03];24(10):795-824. Available from: http://www2. waisman.wisc.edu/phonology/pubs/PUB66.pdf.

26. Carrico B, Samelli AG, Matas CG, Magliaro FCL, Carvallo RMM, Limongi SCO et al. Peripheral hearing evaluation in children with Down syndrome. Audiol., Commun. Res. [Internet]. 2014 Set [citado 2018 Jul 17]; 19(3):280-5. Disponível em: http://www.scielo.br/scielo.php?script $=$ sci arttext\&pid $=$ S2317-64312014000300280\&lng $=$ en\& $\mathrm{nrm}=$ iso\&tlng $=$ en.

27. Zampini L, Fasolo M, Spinelli M, Zanchi P, Suttora C, Salerni N. Prosodic skills in children with Down syndrome and in typically developing children. Int J Lang Commun Disord. 2016;51(1):74-83.

28. O' Leary D, Lee A, O'Toole C, Gibbon F. Perceptual and acoustic evaluation of speech production in Down syndrome: a case series. Clinical Linguistics \& Phonetics. 2020;34(1-2):72-91.

29. Lee MT, Thorpe J, Verhoeven J. Intonation and phonation in young adults with Down syndrome. J Voice. [Internet]. 2009 [cited 2018 Feb. 04]; 23(1):82-7. Available from: https:// www.sciencedirect.com/science/article/pii/ S0892199707000665.

30. Lukowskia AF, Milojevichb HM, Ealesc L. Cognitive functioning in children with Down syndrome: current knowledge and future directions. Adv Child Dev Behav. 2019;56:257-69. 